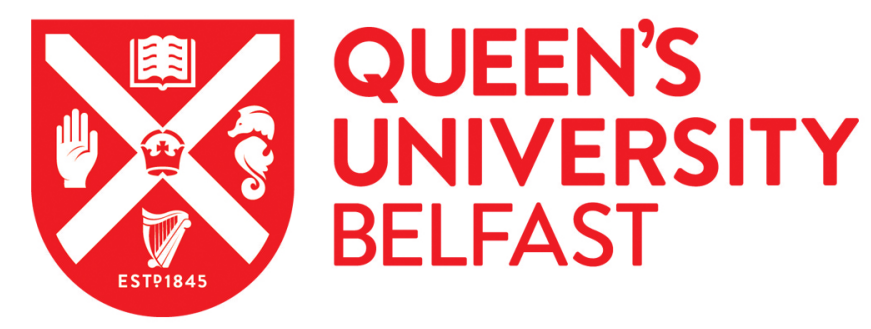

\title{
Stairway to Heaven? Geographies of Space Elevators in Science Fiction
}

Dunnett, O. (2020). Stairway to Heaven? Geographies of Space Elevators in Science Fiction. Roadsides, 3, 4247. https://doi.org/10.26034/roadsides-202000306

\section{Published in:}

Roadsides

Document Version:

Publisher's PDF, also known as Version of record

Queen's University Belfast - Research Portal:

Link to publication record in Queen's University Belfast Research Portal

\section{Publisher rights}

(C) 2020 The Authors

This is an open access article published under a Creative Commons Attribution-NonCommercial-ShareAlike License

(https://creativecommons.org/licenses/by-nc-sa/4.0/), which permits use, distribution and reproduction for non-commercial purposes, provided the author and source are cited and new creations are licensed under the identical terms.

\section{General rights}

Copyright for the publications made accessible via the Queen's University Belfast Research Portal is retained by the author(s) and / or other copyright owners and it is a condition of accessing these publications that users recognise and abide by the legal requirements associated with these rights.

Take down policy

The Research Portal is Queen's institutional repository that provides access to Queen's research output. Every effort has been made to ensure that content in the Research Portal does not infringe any person's rights, or applicable UK laws. If you discover content in the Research Portal that you believe breaches copyright or violates any law, please contact openaccess@qub.ac.uk. 


\title{
Stairway to Heaven? Geographies of the Space Elevator in Science Fiction
}

\author{
Oliver Dunnett
}

Outer space is often presented as a kind of universal global commons - a space for all humankind, against which the hopes and dreams of humanity have been projected. Yet, since the advent of spaceflight, it has become apparent that access to outer space has been limited, shaped and procured in certain ways. Geographical approaches to the study of outer space have started to interrogate the ways in which such inequalities have emerged and sustained themselves, across environmental, cultural and political registers. For example, recent studies have understood outer space as increasingly foreclosed by certain state and commercial actors (Beery 2012), have emphasised narratives of tropical difference in understanding geosynchronous equatorial satellite orbits (Dunnett 2019) and, more broadly, have conceptualised the Solar System as part of Earth's environment (Degroot 2017). It is clear from this and related literature that various types of infrastructure have been a significant part of the uneven geographies of outer space, whether in terms of long-established spaceports (Redfield 2000), anticipatory infrastructures (Gorman 2009) or redundant space hardware orbiting Earth as debris (Klinger 2019). 
Having been the subject of speculation in both engineering and science-fictional discourses for many decades, the space elevator has more recently been promoted as a "revolutionary and efficient way to space for all humanity" (ISEC 2017). The concept involves a tether lowered from a position in geostationary orbit to a point on Earth's equator, along which an elevator can ascend and arrive in orbit. Essentially, it balances the centrifugal forces of Earth's rotation with the effect of gravity to achieve a stable connection between Earth and outer space. It is also theoretically applicable to other planetary bodies, potentially mitigating many of the difficulties associated with launching from, and landing onto, planets and moons across the Solar System. An embryonic form of the space elevator was conceived in the early twentieth century by the Russian spaceflight theorist Konstantin Tsiolkovskii, who was purportedly inspired by the construction of the Eiffel Tower. In the postwar period, the concept

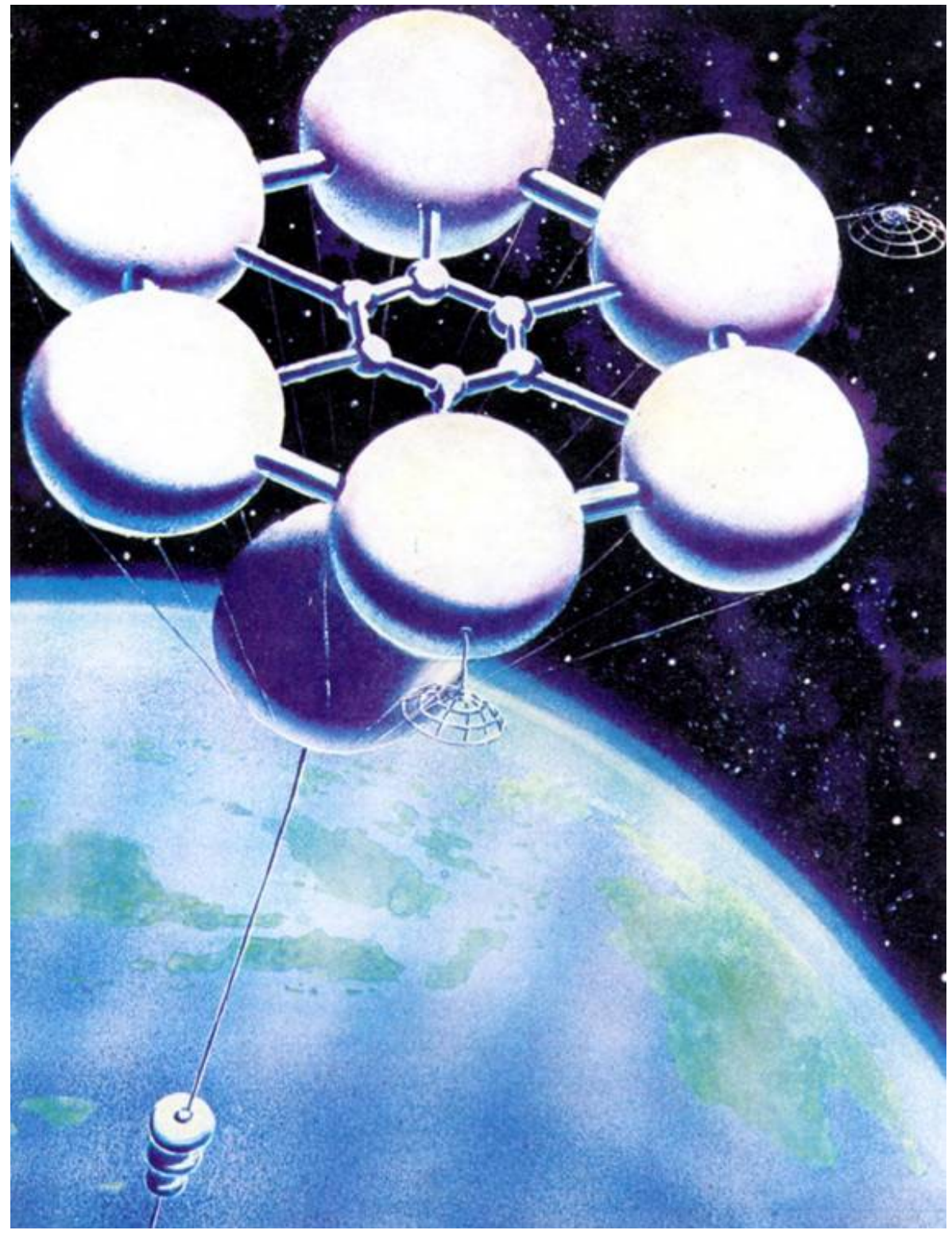

This painting by Alexe Sokolov is one of the earliest known images of a space elevator (Leonov and Sokolov 1967: 25). Source: https://commons. wikimedia.org/wiki/ File:Andrei_Sokolov\%27s painting_of_a_space elevator.jpg. 
was outlined in greater detail by the Russian engineer Yuri Artsutanov (Artsutanov 1960), before attracting broader attention in an article by Jerome Pearson of the US Air Force (Pearson 1975).

Since its initial proposal in various popular-scientific formats, the space elevator (a.k.a. orbital tower, sky-hook or heavenly staircase) has been described in numerous works of science fiction, two of which are the focus of this short article. Arthur C. Clarke's The Fountains of Paradise (1979) popularised the space elevator concept for audiences well beyond the engineering and spaceflight circles in which it was conceived, and remains the archetypal exposition of the idea in fiction. Numerous subsequent iterations have appeared in science-fiction narratives, one of which is Kim Stanley Robinson's Red Mars (1992), which features a space elevator as part of its narrative of human colonisation of Mars. In both cases, the space elevator plays a pivotal narrative role, representing different kinds of geographical, cultural and political ramifications of space travel.

The space elevator in The Fountains of Paradise is conceptualised as a first step in the mass human colonisation of the Solar System. The main part of Clarke's novel assiduously establishes as the setting the island of Sri Kanda, which is loosely based on aspects of Sri Lankan history and geography, and whose society is at a threshold in what is presented as a transition from antiquity to modernity. This is encapsulated in the narrative framing of the space elevator, whose Earth terminus is affixed to the summit of the holy mountain Sri Kanda, itself a model of the actual Sri Lankan mountain, Sri Pada. From here, "for the first time in history," as one character describes, "we shall have a stairway to heaven - a bridge to the stars" (Clarke 1980: 52). In supplanting a monastic site atop Sri Kanda, the space elevator terminus presents technology as a driver of societal progress, and space exploration as the ultimate harbinger of a prosperous future for humanity.

Clarke's novel ends with a far-future vision of a colonised Solar System, with the space elevator becoming "a vertical city", just one spoke in a giant wheel that connects Earth with a vast orbital ring that encircles the globe (Clarke 1980: 226). As such, with the Sun entering a cooler phase in its life-cycle, "the whole terrestrial population had streamed up the equatorial Towers and flowed sunwards towards the young oceans of Venus, [and] the fertile plains of Mercury's Temperate Zone" (Clarke 1980: 224). In this way, the space elevator acts as a bridge to salvation in the cosmos, a triumphant and transformational piece of Earth-space infrastructure. However, considered in the context of Clarke's identity as a western author in a postcolonial space, and noting the significance of the equatorial region to orbital space technologies, The Fountains of Paradise also foregrounds earthly geographies of colonialism and tropicality in the articulation of humanity's possible future in space (Dunnett 2019).

In many ways, Kim Stanley Robinson's Mars trilogy owes an imaginative debt to Clarke, not just in terms of its "hard" science-fiction style of writing, but in its imagined future colonisation of Mars and indeed its narrative exposition of the space elevator concept. This debt is acknowledged in Red Mars by designating the orbital terminus of the Martian space elevator as the asteroid "Clarke," which has, in the novel, been moved into an orbital position above the Martian equator. While the imagined technology of the space elevator is broadly comparable between the two novels, including their 
planetary position on equatorial mountain-tops, their narrative divergences are significant. While Clarke's space elevator represents a utopian bridge to the stars, Robinson's space elevator acts as a catalyst for violent revolution on the Red Planet.

Human colonisation of Mars takes place continuously over the course of the novel and is tied up with the ongoing terraforming of the planet. As such, the pioneering first hundred settlers are joined by larger groups of emigrants from a politically volatile Earth, and the Martian space elevator plays a pivotal role in the acceleration of this process, easing the transportation of people and goods down to the planet's surface. The elevator cable's descent from the orbiting asteroid to the equatorial volcanic dome Pavonis Mons is described ominously in Red Mars - one character "felt as if he were standing on a sea floor observing a fishing line dropped down among them from the plum sea surface" (Robinson 1996: 508). Once the elevator is in place, it causes a huge influx of new colonisers to the Martian surface. These individuals are aligned with the "transnats" on Earth, global corporations that are exerting increasing control over terrestrial politics. The result is "a million people and no law, no law but corporate law" (Robinson 1996: 516).

Red Mars ends with a popular uprising against Earth's pervading influence on Mars. This is encapsulated in the fate of the space elevator, which, through sabotage, is detached from its anchor in space and comes crashing down along the Martian surface, wrapping twice around the planet. One character describes the resultant landform as "an equator just like the one I thought the Earth had when I was four years old. A big black line running right around the planet" (Robinson 1996: 594). As David Valentine has pointed out, the Mars trilogy has been praised both by advocates of planetary colonisation and by critics of utopianism, but nonetheless, the novels are characterised by "mapping terrestrial relations onto the Red Planet" (Valentine 2017: 193). The space elevator in Red Mars, whether through its construction or its downfall, acts as a conduit for such mappings, and thereby reflects contemporary concerns about "the political-economic dimensions of private space activity" (Beery 2012: 25), and, perhaps more alarmingly, the ways in which plans for the colonisation of other planets could render Earth as "something that can be left behind" amid discourses of uncertain environmental futures (Klinger 2019: 10).

Thinking through space infrastructure as culturally and politically arbitrated in specific geographical contexts helps to overcome grandiose projections of space exploration as a technologically mediated panacea for humankind's problems on Earth, or as a gateway to a bright future in the cosmos. This article has suggested that the space elevator could be better understood in, for example, the historical context of colonialism or through contemporary understandings of planetary environmentalism. In this respect, the intersection of scholarly work in critical geography with critical studies of infrastructure, both actual and anticipatory, has much to offer. While space elevators are towards the extreme end of technologically possible alternatives to conventional space travel, their present-day proponents cite them as just one of the ways in which space travel can benefit human society. Thinking critically about imaginative representations of space technology can act as a reminder that space infrastructure, as with many forms of technology, is culturally and politically situated and can be contested across both fictional and critical scholarly registers. 


\section{References:}

Artsutanov, Yuri. 1960. “To the Cosmos by Electric Train." Pravda, 31 July 1960. Available at: http://images.spaceref.com/docs/spaceelevator/Artsutanov Pravda SE.pdf.

Beery, Jason. 2012. "State, capital and spaceships: A terrestrial geography of space tourism." Geoforum 43: 25-34. DOI: https://doi.org/10.1016/i.geoforum.2011.07.013.

Clarke, Arthur C. 1980 [1979]. The Fountains of Paradise. London: Pan.

Degroot, Dagomar. 2017. “'A Catastrophe Happening in Front of Our Very Eyes': The Environmental History of a Comet Crash on Jupiter." Environmental History 22: 23-49. DOI: https://doi.org/10.1093/envhis/emw067.

Dunnett, Oliver. 2019. “Imperialism, Technology and Tropicality in Arthur C Clarke's Geopolitics of Outer Space." Geopolitics. DOI: https://doi.org/10.1080/14650045.201 9.1569632 .

Gorman, Alice. 2009. “The Archaeology of Space Exploration.” In Space Travel and Culture: From Apollo to Space Tourism, edited by Martin Parker and David Bell, 132-45. Oxford: Blackwell.

International Space Elevator Consortium. 2017. "About ISEC - International Space Elevator Consortium." Available at: http://isec.org/about-us/.

Klinger, Julie. 2019. "Environmental Geopolitics and Outer Space." Geopolitics. DOI: https://doi.org/10.1080/14650045.2019.1590340

Pearson, Jerome. 1975. "The orbital tower: A spacecraft launcher using the Earth's rotational energy." Acta Astronautica 2: 785-99. DOI: https://doi.org/10.1016/00945765(75)90021-1.

Redfield, Peter. 2000. Space in the Tropics: From Convicts to Rockets in French Guiana. Berkeley: University of California Press.

Robinson, Kim Stanley. 1996 [1992]. Red Mars. London: HarperCollins.

Leonov, Alexei and Andrei Sokolov. 1967. The Stars are Awaiting Us. Moscow: Molodoia Gvardiia.

Valentine, David. 2017. "Gravity Fixes: Habituating to the Human on Mars and Island Three." HAU: Journal of Ethnographic Theory 7 (3): 185-209. DOI: https://doi.org/10.14318/ hau7.3.012. 
Cite as: Dunnett, Oliver. 2020. "Stairway to Heaven? Geographies of the Space Elevator in Science Fiction." Roadsides 3: 42-47. DOI: https://doi.org/10.26034/roadsides-202000306

\section{Author:}

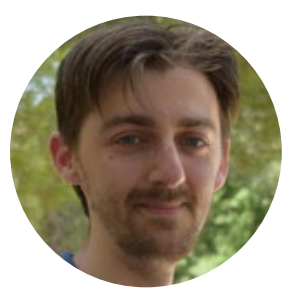

Oliver Dunnett is a lecturer in human geography at Queen's University Belfast, specialising in cultural, historical and political geography. His research focuses on the ways in which the cultures and politics of outer space, science and technology are connected to questions of place, landscape and identity in a variety of local, regional and national contexts. His first book, Geographies of Outer Space in Britain, 1900-2020, is due to be published this year as part of the Routledge research series in historical geography. He has published various journal articles and book chapters, examining topics such as the moral geographies of light pollution in Britain, the ethics of space exploration in the writings of C. S. Lewis and the geopolitics of outer space in the works of Arthur C. Clarke. He has further research interests in literary geographies, critical geopolitics and the geographies of popular culture, particularly the medium of comics and the genre of science fiction. A full publication list can be found at: http://go.qub.ac.uk/ODResearch 
Roadsides is an open access journal designated to be a forum devoted to exploring the social, cultural and political life of infrastructure.

\section{Editorial Team:}

Julie Chu (University of Chicago)

Tina Harris (University of Amsterdam)

Agnieszka Joniak-Lüthi (University of Zurich)

Madlen Kobi (Academy of Architecture, Mendrisio)

Nadine Plachta (Heidelberg University's South Asia Institute, Kathmandu Office)

Galen Murton (LMU Munich and James Madison University, Harrisonburg)

Matthäus Rest (Max-Planck-Institute for the Science of Human History, Jena)

Alessandro Rippa (Tallinn University)

Martin Saxer (LMU Munich)

Christina Schwenkel (University of California, Riverside)

Max D. Woodworth (The Ohio State University)

Collection no. 003 was edited by: Christine Bichsel

Managing editor: Agnieszka Joniak-Lüthi

Copyediting: David Hawkins

Layout: Chantal Hinni and Antoni Kwiatkowski

\section{ISSN 2624-9081}

\section{Creative Commons License}

This work is licensed under a Creative Commons Attribution-NonCommercial-ShareAlike 4.0 International License.

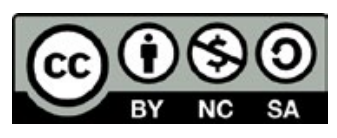

